Article

\title{
Experimental Validation of an FSW Model with an Enhanced Friction Law: Application to a Threaded Cylindrical Pin Tool
}

\author{
Narges Dialami ${ }^{1, *}$, Miguel Cervera ${ }^{1}$ (D), Michele Chiumenti ${ }^{1}$ (D), Antonio Segatori ${ }^{2}$ and \\ Wojciech Osikowicz ${ }^{2}$ \\ 1 International Center for Numerical Methods in Engineering (CIMNE), Universidad Politécnica de Cataluña, \\ Campus Norte UPC, 08034 Barcelona, Spain; miguel.Cervera@upc.edu (M.C.); \\ michele@cimne.upc.edu (M.C.) \\ 2 Sapa AB Technology, Kanalgatan 1, 61281 Finspang, Sweden; Antonio.Segatori@sapagroup.com (A.S.); \\ Wojciech.Osikowicz@sapagroup.com (W.O.) \\ * Correspondence: narges@cimne.upc.edu; Tel.: +34-93-401-6529
}

Received: 6 October 2017; Accepted: 6 November 2017; Published: 10 November 2017

\begin{abstract}
This work adopts a fast and accurate two-stage computational strategy for the analysis of FSW (Friction stir welding) processes using threaded cylindrical pin tools. The coupled thermo-mechanical problem is equipped with an enhanced friction model to include the effect of non-uniform pressure distribution under the pin shoulder. The overall numerical strategy is successfully validated by the experimental measurements provided by the industrial partner (Sapa). The verification of the numerical model using the experimental evidence is not only accomplished in terms of temperature evolution but also in terms of torque, longitudinal, transversal and vertical forces.
\end{abstract}

Keywords: FSW; threaded pin; numerical model; experimental validation

\section{Introduction}

Friction stir welding (FSW) is a solid state joining technology in which friction and plastic dissipation are sources of heat generation and material softening.

The tool pin profile has a remarkable effect on the friction between the tool and the workpiece and the foremost effect on the plastic deformation of the surrounding material. FSW pin tools are often featured with thread forms as they are beneficial for improving the tool performance and contribute to an effective material transportation near the weld and the generation of a defect free stir zone [1].

Pin tools with threaded features are often used to investigate the relationship between the tool and the microstructural properties obtained using different welding conditions.

In [2], thread pins are used for friction stir welding of two aluminium alloys: AA7050-T7451 and AA6061-T651. They investigate the effect of the thread on the process in terms of in-plane reactions on the pin tool, torque, temperature and the quality of welds.

In [1], heat treatable AA6061 and non-heat treatable AA5086 aluminum alloys are welded by using three different pin tools. It is found that FSW using threaded cylindrical pins provides better material flow between two alloys among others.

In [3], the influence of the tool geometries upon the axial and translational forces, temperature and mechanical properties for AA7075-T6 is studied. In their experimental work, threaded tapered, non-threaded triangular and non-threaded cylindrical pins are considered.

In [4], the effect of tool geometry on friction stir welding of polyethylene-polypropylene is investigated. Threaded cylindrical, squared, triangular and straight cylindrical pin shapes are 
considered. Interaction effects of welding variables, including rotational speed and traverse speed are studied.

In [5], a half-threaded pin tool to enhance the material flow at the lap interface is manufactured. The effect of manufactured pin on the process is compared with that of full-threaded pin in terms of temperature, bonding and material flow. It is observed, for instance, that the peak temperature during the process using the half-threaded pin is lower than that using the full-threaded pin.

In [6], Colegrove et al. use the computational fluid dynamics (CFD) code, FLUENT, to model the 3D metal flow in FSW using a threaded pin. It is found that the model generates an excessive amount of heat, leading to over-prediction of the weld temperature.

Atharifar et al. [7] analyze the viscous and inertia loads applied to the FSW tool by varying the welding parameters using FLUENT. A right-handed one-way thread pin tool with a concaved, smooth shoulder is considered to simulate the material flow and heat transfer in the FSW of AA6061.

Even though numerous studies, mainly experimental, of the effect of pin threads on the weld have been carried out, there is an urgent need for a fast and accurate numerical model for the analysis of the FSW process. This model should contain a suitable friction model to properly describe the tribological condition at the tool/workpiece interface, capable of considering real process behavior such as the effect of non-uniform pressure distribution under the tool.

A 3D finite element analysis is able to deal with several process complexities such as a concave shoulder, tool tilt and threaded pin profiles. However, the large computational cost makes it inconceivable as a routinely used design tool [8]. In previous works of the authors, a robust and fast numerical model was developed to study FSW under different welding conditions [9-15]. A fully coupled thermo-mechanical model together with an enhanced friction law was addressed to provide a more realistic thermo-mechanical response in comparison with the existing models. The model took the benefits of an apropos kinematic framework combing Arbitrary Lagrangian Eulerian (ALE), Eulerian and Lagrangian formulations for the stir zone, the workpiece and the pin-tool, respectively. A two-stage speed-up strategy was incorporated to reduce the simulation time while preserving the accuracy of the results.

In the present work, the model previously developed by the authors is adopted for the simulation of a FSW process with a cylindrical threaded pin tool. The use of an apropos kinematic framework permits dealing with arbitrary pin shapes as the threaded pin tool, without the necessity of using a re-meshing procedure due to the large deformation of the material around the threaded pin tool. Moreover, it facilitates the application of the boundary conditions. The enrichment of the model with an enhanced friction law permits to accurately predict not only the temperature field but also the torque and forces exerted by the tool in all the directions. This is mostly lacking in previous works in the FSW field. The use of a two-stage speed-up strategy is especially important when simulating industrial cases, as the model is $3 \mathrm{D}$ and a large number of elements are used in the discretization of the geometry. It is shown here that the framework, formulation and computational strategy are not only applicable to featureless pins but also to pins with features such as threads. The analyses are calibrated and validated through the experimental measurements performed by the industrial partner (Sapa) for aluminum alloy AA6063-T6. The correlations obtained by means of this comparison not only validate the model but also provide insight regarding the effects of the threaded pins upon torque, forces and temperature field. Also, the differences between threaded and featureless cylindrical pins of similar dimensions are studied in detail.

The paper is structured as follows: In Section 2, the overall solution strategy applied for simulation of FSW process using cylindrical threaded pin tool is summarized. In Section 3, the numerical assessment and the calibration of the model using the experimental data are presented. Section 4 is devoted to the comparison of the weld obtained using threaded and featureless cylindrical tool pins. 


\section{The Solution Strategy}

In this work, a local analysis of the FSW process is performed. This means that the domain surrounding the thermo-mechanically affected zone (TMAZ) and the tool are considered in the simulation. The tool rotates rigidly with a constant speed and the plate moves with the advancing velocity opposite to the welding direction.

The governing equations and the boundary conditions used for the definition of the transient coupled thermo-mechanical problem are summarized in Table 1. The nomenclature for the variables and properties involved is listed in Table 2. Additional details on the formulation can be found in References $[9,10]$.

Table 1. Balance and constitutive equations.

\begin{tabular}{ccc}
\hline & Mechanical Problem & \\
\hline$\nabla \cdot \mathbf{s}+\nabla p+\rho_{0} \mathbf{b}=\mathbf{0}$ & Momentum balance equation \\
$\nabla \cdot \mathbf{v}=0$ & Continuity equation \\
$\boldsymbol{\sigma}=p \mathbf{I}+\mathbf{s}$ & Stress split \\
$\dot{\varepsilon}=\nabla^{s} \mathbf{v}$ & Kinematic equation \\
$\mathbf{s}=2 \mu_{e f f} \dot{\varepsilon}$ & Constitutive equation \\
$\mu_{\text {eff }}=\mu(\sqrt{2}\|\dot{\varepsilon}\|)^{m-1}$ & Norton-Hoff model \\
\hline \multicolumn{2}{c}{$\rho_{0} c\left(\frac{1}{\alpha} \frac{d T}{d t}+\left(\mathbf{v}-\mathbf{v}_{\text {mesh }}\right) \cdot \nabla T\right)+\nabla \cdot \mathbf{q}=D_{\text {mech }}$} & \\
$\mathbf{q}=-k \nabla T$ & \\
$D_{\text {mech }}=\beta \mathbf{s}: \dot{\varepsilon}$ & & \\
$q_{\text {conv }}=h\left(T-T_{\text {env }}\right)$ & Thermal Problem & Heat flux \\
$q_{\text {cond }}=h_{\text {cond }}\left(T-T_{\text {tool }}\right)$ & & Viscoplastic dissipation \\
\end{tabular}

Table 2. Nomenclature.

\begin{tabular}{cc}
\hline $\mathbf{s}$ & Stress deviator \\
$p$ & Pressure \\
$\rho_{0}$ & density in the reference configuration \\
$\mathbf{b}$ & body forces vector per unit of mass \\
$\mathbf{v}$ & Velocity field \\
$\mathbf{\sigma}$ & Cauchy's stress tensor \\
$\dot{\varepsilon}$ & Strain rate \\
$\mu_{e f f}$ & Effective viscosity \\
$\mu$ & Viscosity parameter \\
$m$ & Viscosity exponent \\
$c$ & Specific heat \\
$T$ & Temperature \\
$\mathbf{v}_{\text {mesh }}$ & Velocity of the mesh \\
$k$ & Thermal conductivity \\
$\beta$ & Fraction of plastic dissipation converted into heat \\
$h_{\text {conv }}$ & Heat transfer coefficient by convection \\
$h_{\text {cond }}$ & Heat transfer coefficient by conduction \\
$\alpha$ & Speed-up factor \\
$T_{\text {env }}$ & Environmental temperature \\
$T_{\text {tool }}$ & Tool temperature \\
\hline
\end{tabular}

A two-stage simulation strategy is adopted [14]. A coupled thermo-mechanical problem is solved in both stages $[13,16]$.

The first stage consists of a "forced" transient analysis aiming to reach the steady-state quickly. This objective is achieved by increasing the thermal diffusivity in the energy balance equation. 
An acceleration parameter is used to reduce the inertia term to speed-up this transient stage and reach the steady-state temperature field in a decreased number of time-steps.

The second stage performs a transient analysis in which the temperature and velocity field obtained in the first stage are considered as initial condition.

In the first stage, an Eulerian framework is adopted for the workpiece. Therefore, no periodic stage due to the rotating movement of the tool is assumed. In the second stage, an apropos kinematic framework is adopted taking advantage of combining ALE, Eulerian and Lagrangian formulations [9,10]. The Lagrangian framework is used for the rotating pin, the ALE framework is considered at the stir zone of the work-piece (TMAZ), and the Eulerian framework is used in the remaining part of the work-piece. This allows the analysis of non-cylindrical pin shapes presenting the periodic solution due to the rotation of the tool.

The two-stage speed-up strategy performs the entire simulation preserving the capabilities of the original model to predict FSW forces and torque for any types of pin shape in addition to the material flow visualization [14].

Both plastic dissipation and friction are considered as the sources of heat generation. Friction is modelled by a modified Norton's friction model developed by authors in [15]. This model considers the effect of a non-uniform pressure distribution under the tool (see Figure 1 for a qualitative presentation of pressure distribution around the tool) which results in higher friction in front of the tool and lower friction at the rear of the tool.

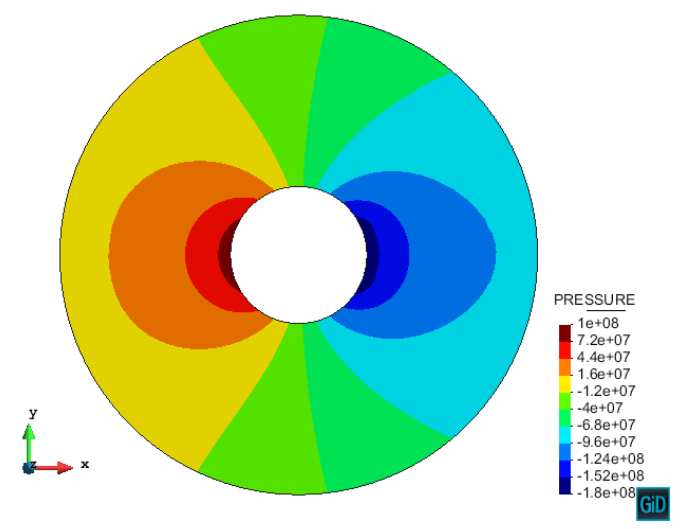

Figure 1. Pressure distribution considering a fully slip contact condition (reproduced from [15]).

The modified Norton's friction law reads:

$$
\boldsymbol{\tau}_{T}=a(x, T)\left\|\Delta \mathbf{v}_{T}\right\|^{q-1} \Delta \mathbf{v}_{T}=a(x, T)\left\|\Delta \mathbf{v}_{T}\right\|^{q} \mathbf{n}
$$

where $\boldsymbol{\tau}_{T}$ is the friction shear stress, $0 \leq q \leq 1$ is the sensitivity parameter and $\Delta \mathbf{v}_{T}$ is the relative sliding velocity between the tool and the workpiece contact surfaces. $\mathbf{n}=\frac{\Delta \mathbf{v}_{T}}{\left\|\Delta \mathbf{v}_{T}\right\|}$ is the sliding direction. The non-uniform consistency parameter $a(x, T)$ is defined by the following expression, to be considered at the tool-workpiece interface, as:

$$
a(x)=0.5\left(a_{\max }+a_{\min }+\left(a_{\max }-a_{\min }\right) \tanh \frac{x}{R / 6}\right)
$$

being $x$ the position of each point located at the tool/workpiece interface, with respect to the rotation axis, projected along the welding direction and $R$ the shoulder radius. Friction tractions vary from the maximum value at the front side of the shoulder to the minimum value at the rear side. Since the temperature in the working zone does not vary significantly, the maximum $\left(a_{\max }\right)$ and minimum $\left(a_{\min }\right)$ consistency parameters are assumed to be dependent on the average working temperature only. 


\section{Validation of Numerical Model from Experimental Data}

In this section, the numerical simulation of the FSW process is performed for a threaded pin tool. The results obtained using the modified Norton's friction model are compared with the experimental measurements performed by the industrial partner (Sapa).

The workpiece geometry is shown in Figure $2\left(300 \times 50 \times 10 \mathrm{~mm}^{3}\right)$. The diameter of the tool shoulder is $18 \mathrm{~mm}$. The average diameter and height of the tool pin are $7 \mathrm{~mm}$ and $4 \mathrm{~mm}$, respectively. Figure 3 shows the experimental settings including the FSW robot, workpiece, tool, clamping system and thermocouples. The process parameters are: advancing velocity $=400 \mathrm{~mm} / \mathrm{min}$ and tool rotation speed $=600 \mathrm{rpm}$. The material used in this test is aluminium alloy (AA6063-T6). The temperature-dependent thermo-mechanical properties are shown in Figure 4.

Figure 2 shows the position of the thermocouples in a transversal section of the workpiece with respect to the weld line. Their distance in $\mathrm{mm}$ with respect to a reference axis located at top left on the weld line is: A1(170,11,-5), A3(175,11,-2), A5(170,5,-5), A6(170,0,-3).

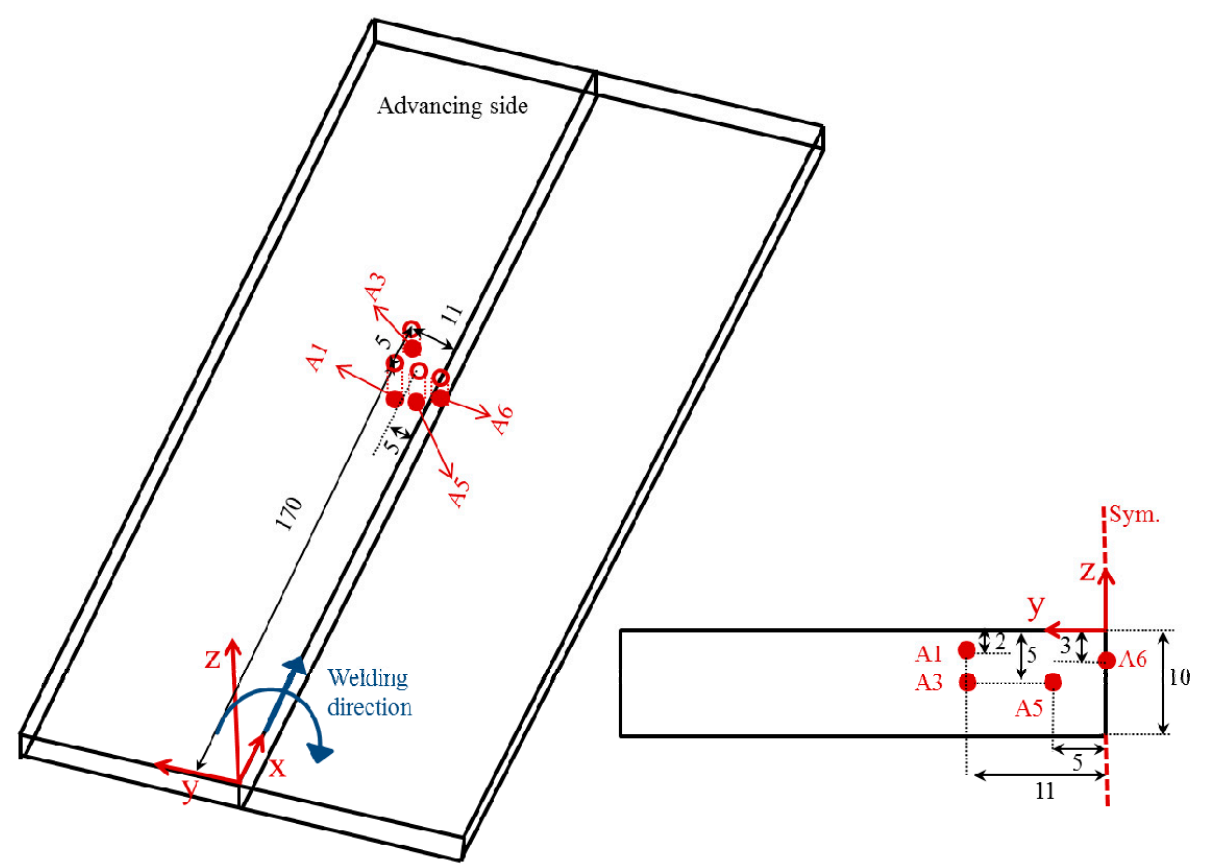

Figure 2. Workpiece geometry and the location of the thermocouples (in $\mathrm{mm}$ ).
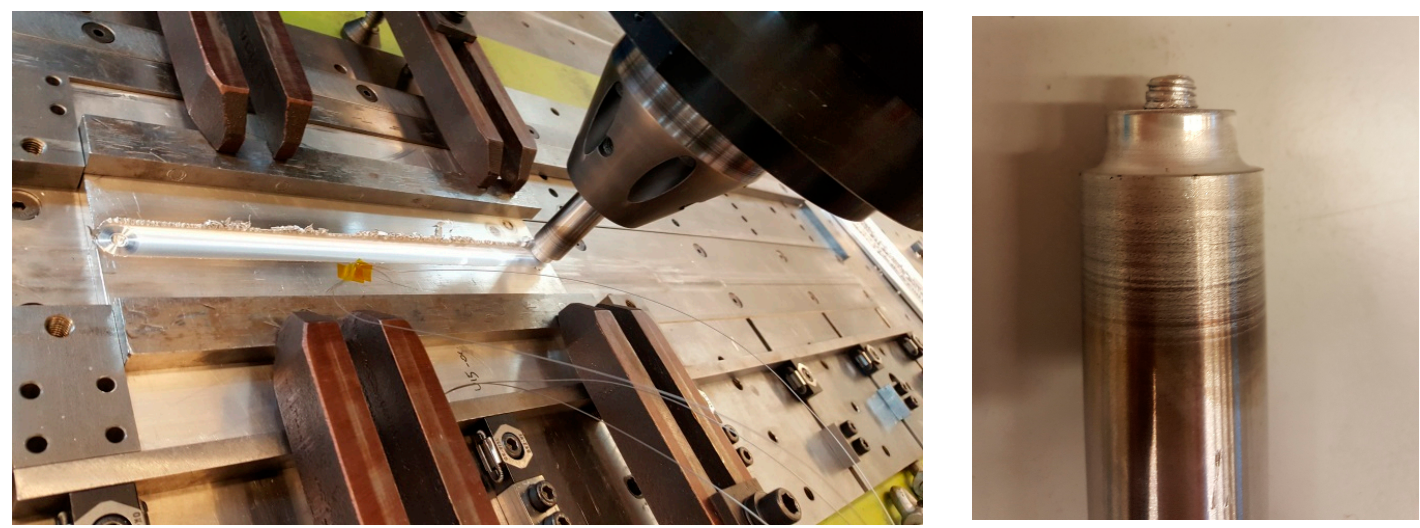

Figure 3. Experimental setting and pin detail. 


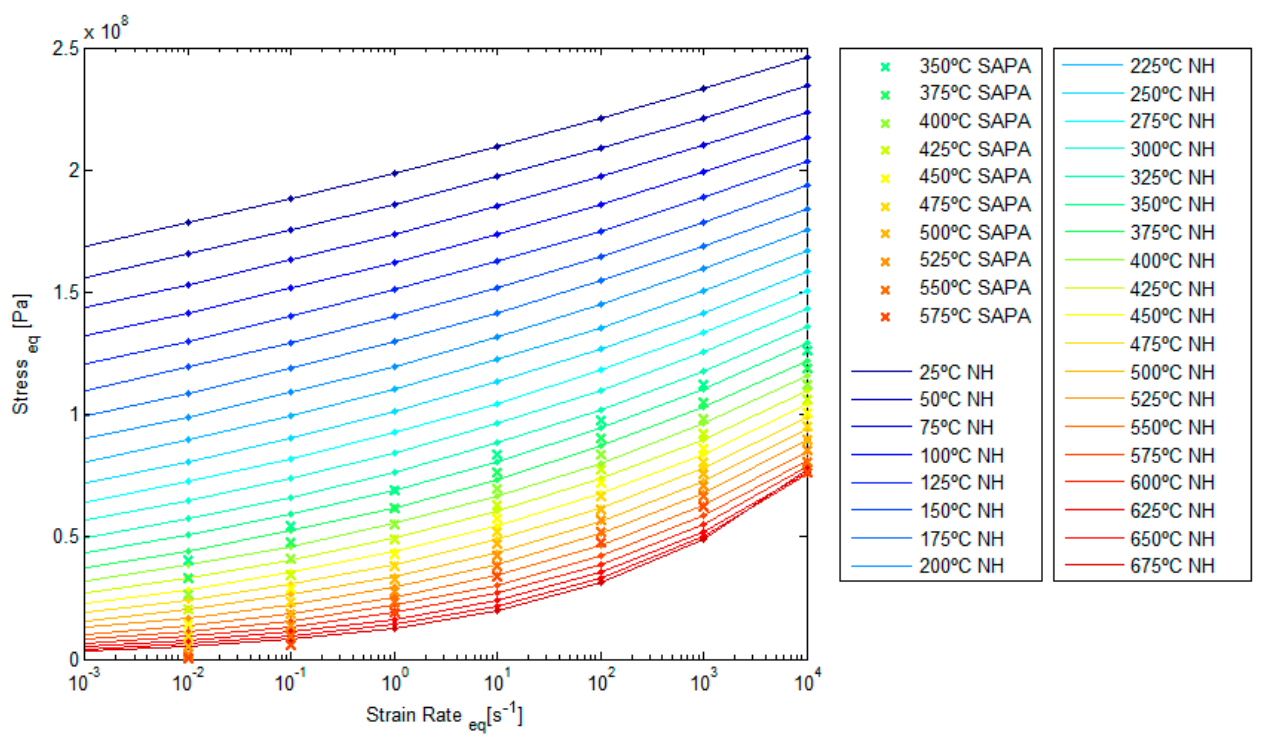

Figure 4. Material characterization.

The simulation considers a domain of $50 \times 50 \times 10 \mathrm{~mm}^{3}$. The tool advances in the $x$ direction of the reference axes. It is assumed that $70 \%$ of the plastic dissipation is converted into heat $[17,18]$.

Friction parameters $a_{\min }$ and $a_{\max }$ at the tool/workpiece interfaces (both pin and shoulder) are determined from the calibration of the friction model by matching the numerical results with the experimental data in terms of temperature evolution and process forces.

The analysis adopts $a_{\min }=5 \times 10^{7}$ and $a_{\max }=10^{9}$ at tool/workpiece interfaces. A vertical velocity of $2.4 \mathrm{~mm} / \mathrm{s}$ is applied on the tool in order to obtain the vertical force exerted on the tool with the experiments.

The heat transfer coefficient, defining the heat loss by convection through the surrounding environment is: $h_{\text {conv }}=10 \mathrm{~W} / \mathrm{m}^{2} \cdot \mathrm{K}$ where the environment temperature is $T_{\text {env }}=20^{\circ} \mathrm{C}$.

The heat transfer coefficient by conduction (Newton's law) between the workpiece and the back-plate has been set to $h_{\text {cond }}=2500 \mathrm{~W} / \mathrm{m}^{2} \cdot \mathrm{K}$.

The values of heat loss by convection and conduction are obtained from series of calibration tests. The calibrated values are in the expected range. Typical values of heat transfer coefficients reported in the literature range from $h_{\text {cond }}=350 \mathrm{~W} / \mathrm{m}^{2} \cdot \mathrm{K}$ in Chao et al. [19] to $h_{\text {cond }}=5000 \mathrm{~W} / \mathrm{m}^{2} \cdot \mathrm{K}$ in Khandkar et al. [20].

Note that radiation is an important heat loss mechanism at the Heat Affected Zone (HAZ), due to the high temperature field induced by the heat source. The radiation heat flux $q_{\text {rad }}$ can be calculated using Stefan-Boltzmann's law: $q_{\mathrm{rad}}=\sigma \varepsilon\left(T^{4}-T_{\text {env }}^{4}\right)$. The contribution of heat radiation can be also expressed as $q_{\text {rad }}=h_{\text {rad }}\left(T-T_{\text {env }}\right)$; where $h_{\text {rad }}(T)=\sigma \varepsilon\left(T^{3}+T^{2} T_{\text {env }}+T T_{\text {env }}^{2}+T_{\text {env }}^{3}\right)$.

Heat is lost through the environment by a combination of convection and radiation. In practice, it is difficult to discriminate the effects of both heat transfer modes. For this reason, the numerical model assumes a combined heat transfer law, accounting for both heat convection and radiation: $q_{\text {conv }}(T)=h_{\text {conv }}\left(T-T_{\text {env }}\right)$. In this case, $q_{\text {conv }}$ represents the heat flux due to the simultaneous convection and radiation mechanisms, and $h_{\text {conv }}$ is the corresponding equivalent heat transfer coefficient.

The mesh used in the simulation consists of 70,000 nodes and 400,000 tetrahedral elements. The mesh resolutions at the tool and the workpiece are shown in Figure 5. A finer mesh is used in the vicinity of the pin-tool to capture the high temperature gradient in the TMAZ and to accurately define the geometry details. 
In order to boost the convergence rate of this highly non-linear and coupled thermo-mechanical problem, a piecewise linearized Norton-Hoff model for different temperatures and strain rate values is assumed [14].

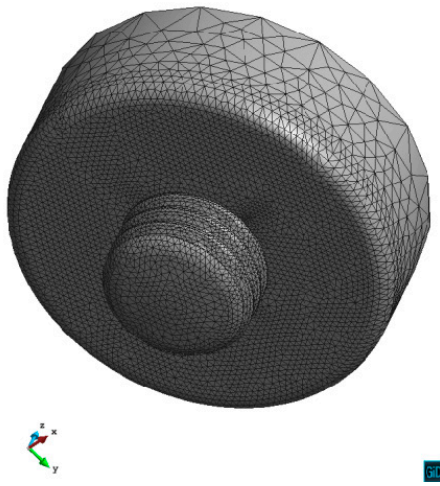

(a)

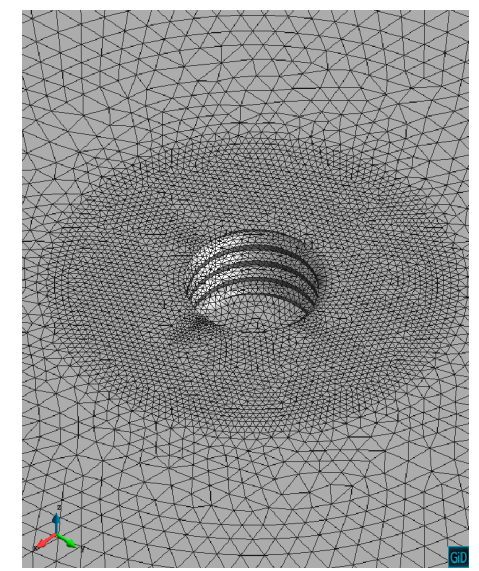

(b)

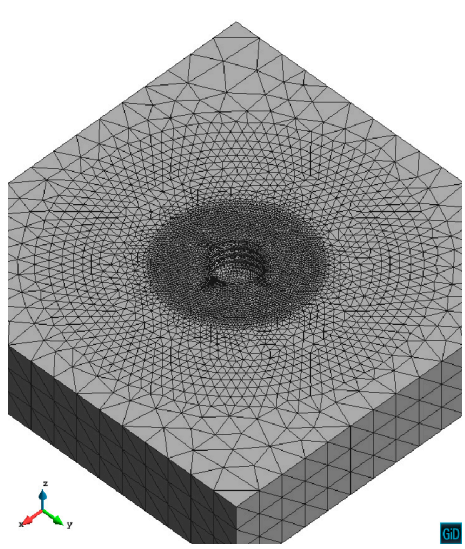

(c)

Figure 5. 3D tetrahedral mesh used: (a) the tool; (b) the workpiece (detail at the stir zone) and (c) the workpiece (larger view).

The agreement between the resulting values of torques, longitudinal, transversal and vertical forces obtained from the numerical model and the experimental measurements is significantly noticeable. Thanks to the friction model proposed by the authors, the overall numerical model is able to predict the transversal forces in agreement with the experimental data, while the commonly used friction laws such as Coulomb or Norton are incapable of capturing it [15]. In this work, the effect of the non-uniform pressure distribution below the tool translates into a non-uniform distribution of plastic dissipation, temperatures and friction tractions. This non-uniformity allows for the development of the transversal force up to the actual value recorded in the experimental measurements. Both experimental and numerical outcomes predict transversal forces higher than longitudinal forces.

Hence, the proposed framework for the numerical simulation of FSW process is capable of capturing accurately the mechanical results (Table 3). This also vouches for the robustness of our friction model proposed for the FSW.

The total processing time on an Intel core i7 processor is approximately $10 \mathrm{~h}$.

Table 3. Forces and torque.

\begin{tabular}{ccc}
\hline $\boldsymbol{q}=\mathbf{0 . 1} ; \boldsymbol{V}_{\boldsymbol{z}}=-\mathbf{0 . 0 0 2 4}$ & Numerical Model: $\boldsymbol{a}_{\mathbf{m a x}}=\mathbf{1} \times \mathbf{1 0}^{\mathbf{9}} ; \boldsymbol{a}_{\mathbf{m i n}}=\mathbf{5} \times \mathbf{1 0}^{\mathbf{7}}$ & Measurements: Sapa WT10 \\
\hline Torque $(\mathrm{N} \cdot \mathrm{m})$ & 64 & 62 \\
Longitudinal force (N) & 810 & 700 \\
Transversal force (N) & 1300 & 1000 \\
Vertical force (N) & 8200 & 8000 \\
\hline
\end{tabular}

Figure 6 illustrates the temperature evolution at the four thermocouples located in the workpiece. In this figure, the comparison between numerical (Num) and experimental (Exp) results is presented. The response of the numerical model is found to be in a good agreement with the experimental measurements. Both experimental and numerical outcomes predict higher maximum temperature in the weld line decreasing with distance from the weld line and top surface.

In this work, the experimental data is provided at steady-state. Therefore, the transient simulation is performed until the (periodic) steady-state is reached. The maximum temperature recorded during the welding provides information indicating whether the process has attained the (periodic) steady-state [21,22]. Under these conditions, a comparison between the temperature fields obtained from the numerical simulation and the experimental measurements is performed. 


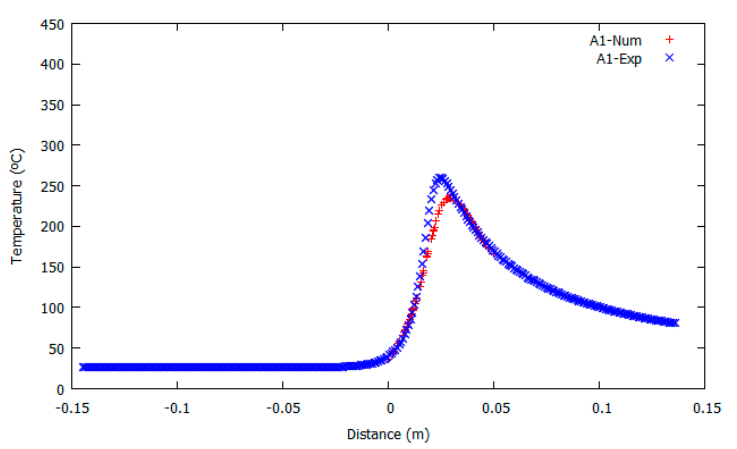

(A1)

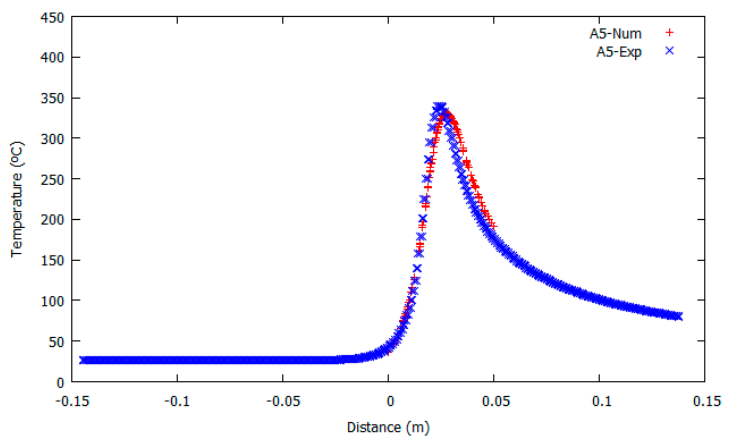

(A5)

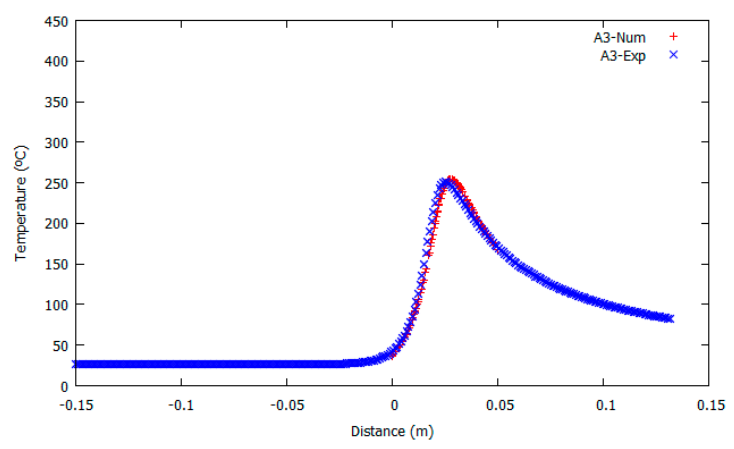

(A3)

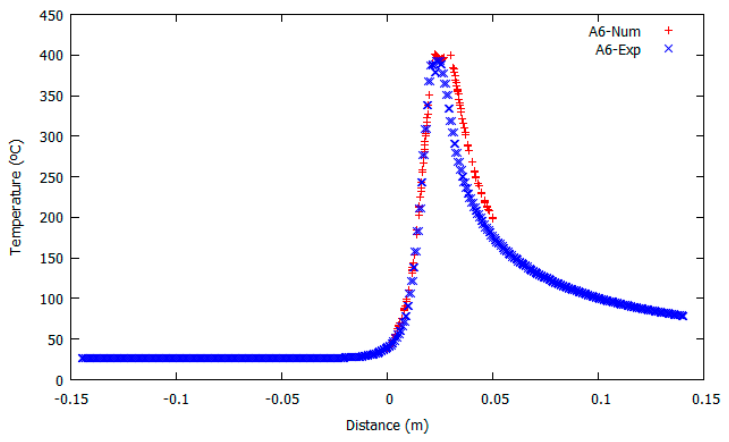

(A6)

Figure 6. Temperature evolution in 4 thermocouples $(\mathbf{A 1}, \mathbf{A} 3, \mathbf{A 5}, \mathbf{A 6})$ located in the workpiece.

Figure 7 shows the temperature field at steady-state on the workpiece surface. The temperature distribution reveals a lower temperature at the head of the pin than the rear side. Thus, the flow stress is higher where the material is hotter. Figures 8 and 9 show the velocity and plastic dissipation contour fills computed from the numerical model. It can be clearly seen that the numerical model is able to represent the non-uniform distribution of the mentioned fields due to the use of the enhanced friction model. This non-uniformity results in the appearance of the transversal forces exerted on the tool.

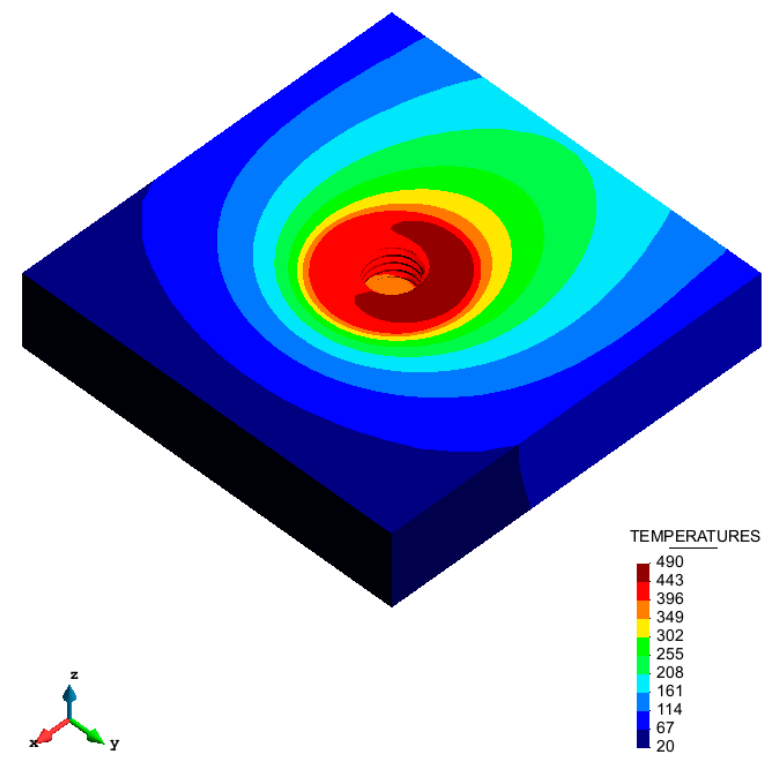

Figure 7. Temperature contour fills. 


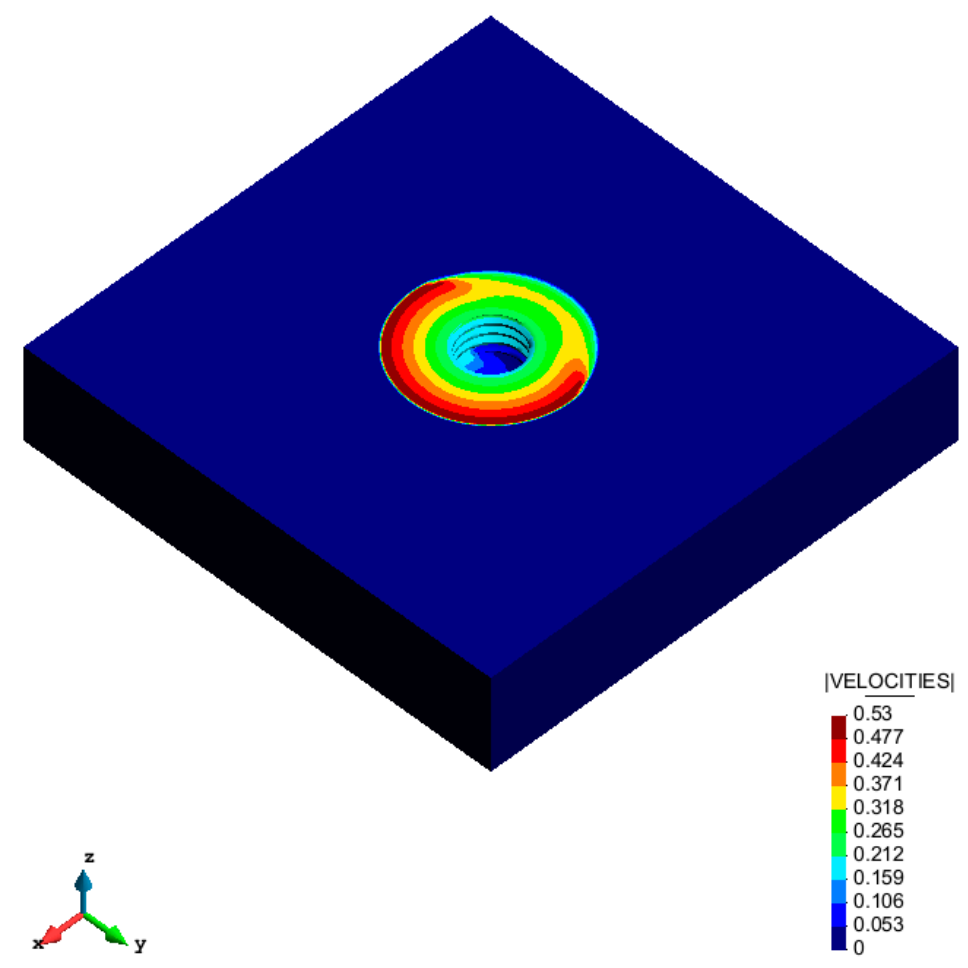

Figure 8. Velocity contour fills.

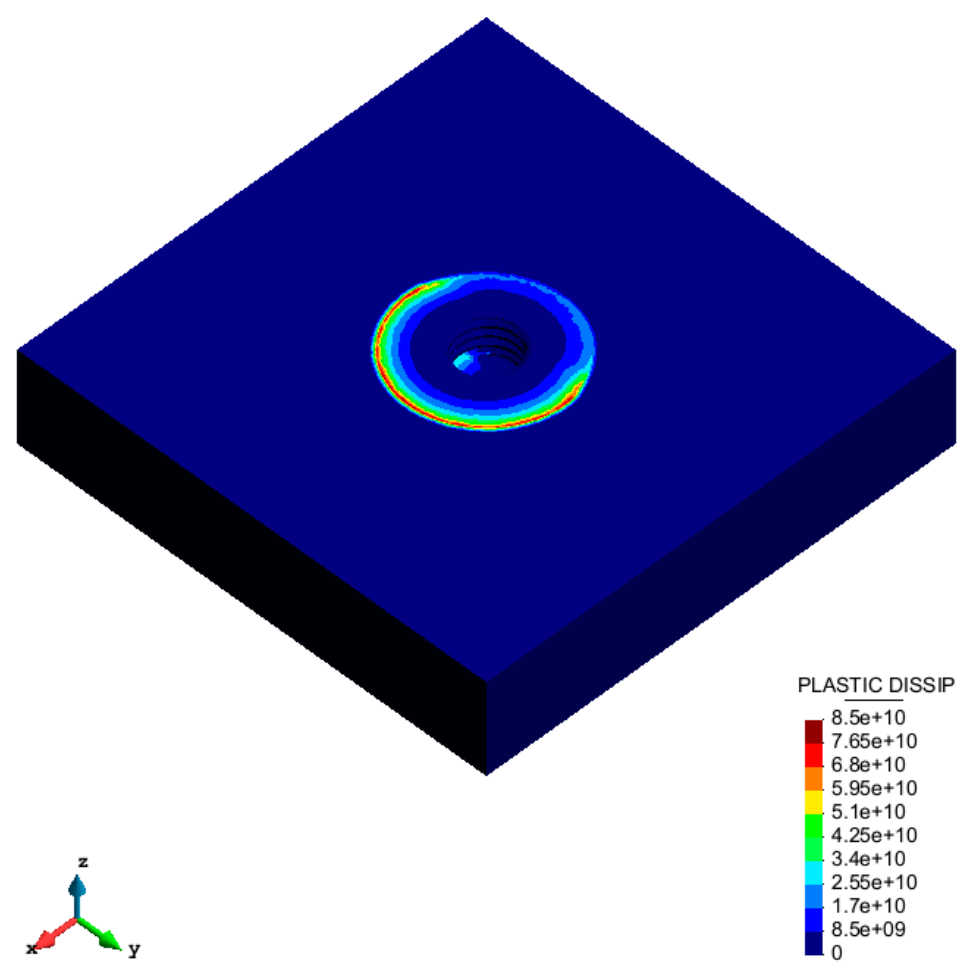

Figure 9. Plastic dissipation contour fills.

The temperature contour fill on the tool surface is displayed in Figure 10. Note that the temperature varies between $360^{\circ} \mathrm{C}$ and $455^{\circ} \mathrm{C}$. This shows that the temperature dependent parameters of the material and friction models vary only within this range of temperature at the TMAZ. 


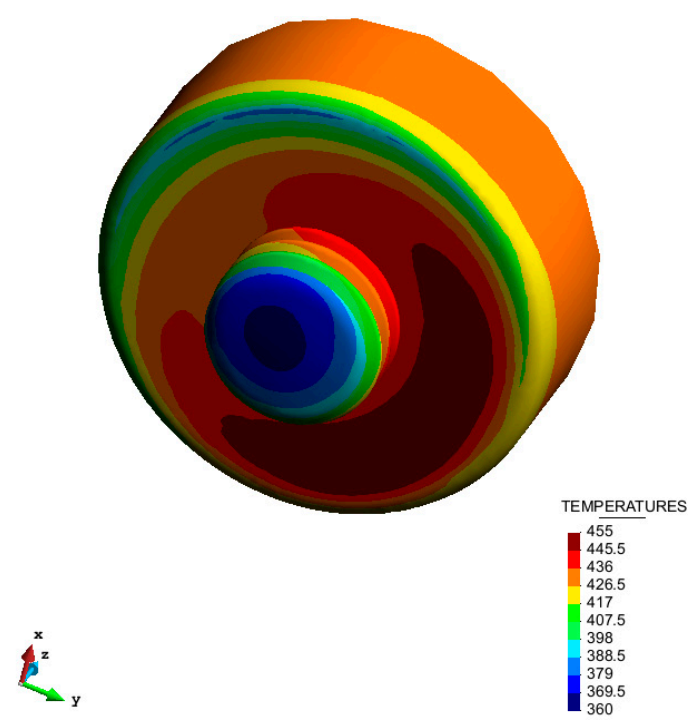

Figure 10. Temperature distribution on the tool.

\section{FSW (Friction Stir Welding) with Featureless and Threaded Cylindrical Pin}

In this section, the thermo-mechanical results obtained for a featureless cylindrical pin (presented in [15]) are compared with the ones presented in the previous section for a threaded cylindrical pin. The comparison between these two cases is carried out after validating both simulations using threaded and featureless pins against the experimental measurements. The coupled thermo-mechanical model enriched with the enhanced friction model and the two-stage speed-up strategy used in both cases is identical. Thanks to the apropos kinematic framework adopted, the model can handle arbitrary pin shapes such as threaded profiles.

In both cases, the workpiece geometry, material properties and process parameters (advancing and rotating speed) are identical. The tool tilt angle is kept constant at $0^{\circ}$ and the plunging depth of the pin-shoulder into the workpiece is negligible during the full welding process. The diameter and height of the featureless tool pin are $7 \mathrm{~mm}$ and $4 \mathrm{~mm}$, respectively.

The values $a_{\min }=4 \times 10^{7}$ and $a_{\max }=8 \times 10^{8}$ are used at tool/workpiece interfaces using the featureless tool while using threaded tool higher values of consistency parameters are used $\left(a_{\min }=5 \times 10^{7}\right.$ and $\left.a_{\max }=10^{9}\right)$. The higher values of consistency parameters translate into an increase in the friction value which is consistent with the effect of the threads in a FSW process.

The vertical velocity is $2.5 \mathrm{~mm} / \mathrm{s}$ in the case of featureless tool pins in order to obtain the applied vertical loading. It is slightly higher than the value applied for the threaded case.

The results for forces and torque using both types of tool profile are presented in Table 4 . Both cases present similar results, with lower values of forces and torque due to the thread effect, while maintaining a good agreement with the experimental measurements. A similar trend is also observed in reference [2] where the effects of pin features on material flow and friction stir weldability of two different aluminum alloys are studied. It is shown there that the featureless pin results in higher forces and torque than the threaded pin.

Table 4. Forces and torque (comparison between FSW process using threaded and featureless pin).

\begin{tabular}{ccccc}
\hline & \multicolumn{2}{c}{ Threaded Pin } & \multicolumn{2}{c}{ Featureless Pin } \\
\cline { 2 - 5 } & Numerical Model & Measurements & Numerical Model & Measurements \\
\hline Torque (N·m) & 64 & 62 & 64 & 64 \\
Longitudinal force (N) & 810 & 700 & 870 & 500 \\
Transversal force (N) & 1300 & 1000 & 1700 & 1400 \\
Vertical force (N) & 8200 & 8000 & 8500 & 8200 \\
\hline
\end{tabular}


Figure 11 presents the temperature contours under the tool on the workpiece for both threaded and unthreaded tool pins. In the case of threaded pin, the difference in the temperature distribution on the retreating side and advancing side is more visible than in the unthreaded case. Hence, the friction model proposed is able to capture the non-uniformly distributed temperature around the tool.

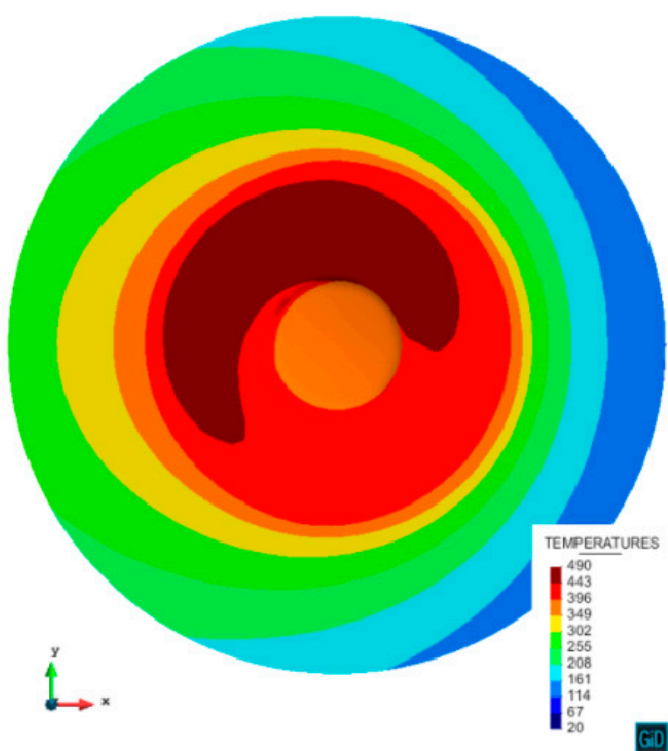

(a)

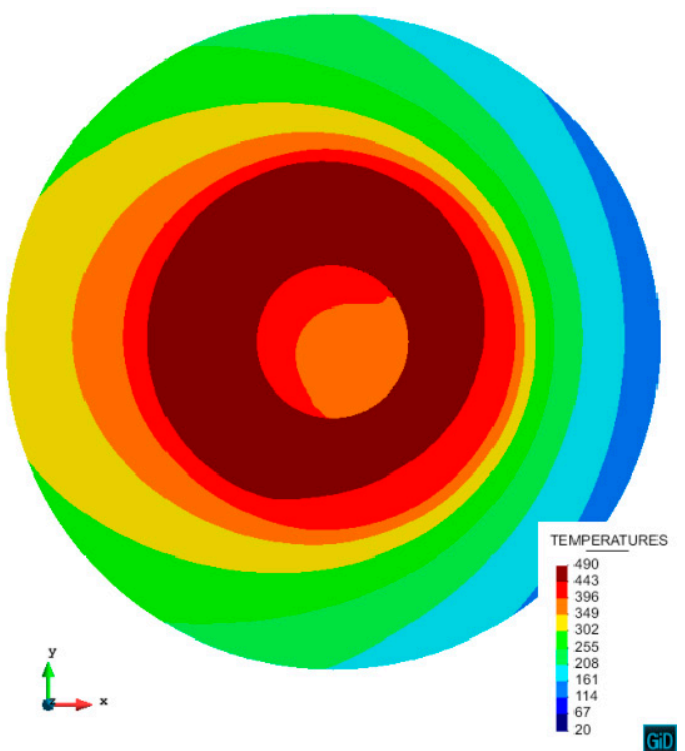

(b)

Figure 11. Temperature distribution under the tool. (a) Threaded pin; (b) Featureless pin.

The distribution of the plastic dissipation under the tool shoulder on the workpiece using both tool pins is compared in Figure 12. The plastic dissipation is higher in front of the tool when using featureless pin and it is higher in the rear of the tool if threaded tool pin is considered.

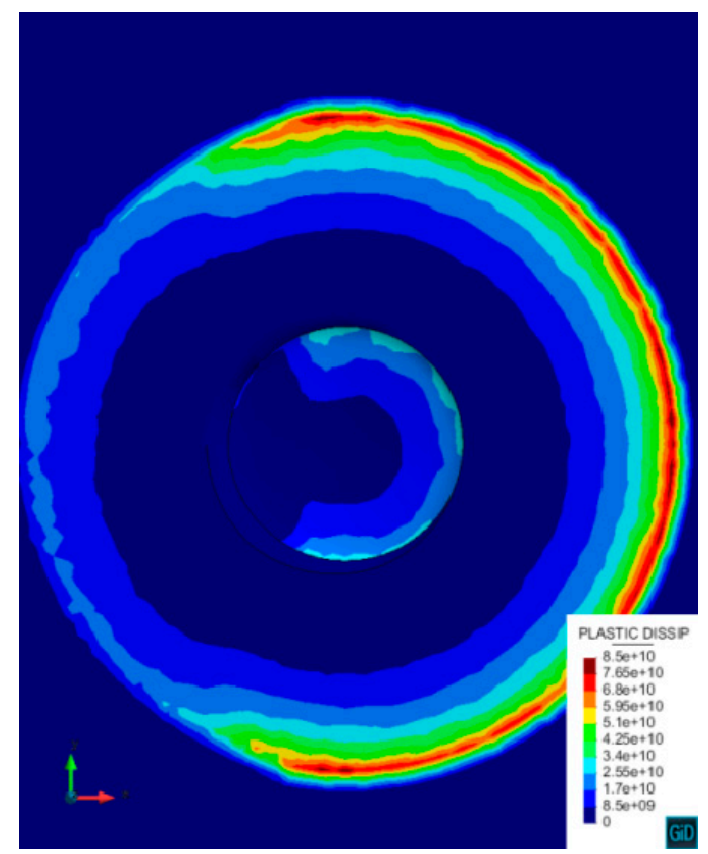

(a)

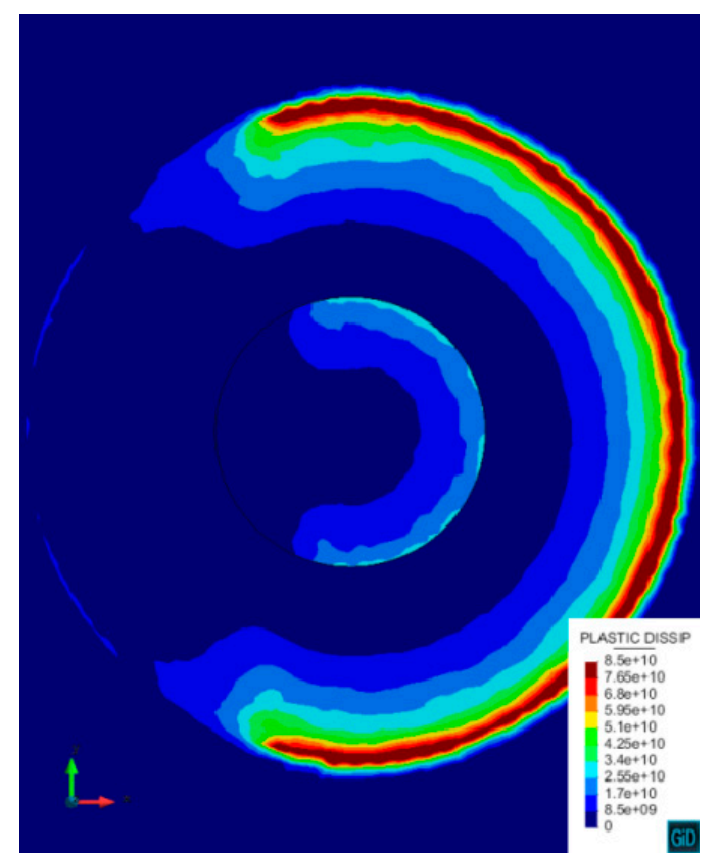

(b)

Figure 12. Plastic dissipation contours under the tool. (a) Threaded pin; (b) Featureless pin. 
Figure 13 presents the velocity streamlines of three points located on a line $5 \mathrm{~mm}$ away from the rotation axis on the advancing side of both featureless and threaded pin tool and $2 \mathrm{~mm}$ away from the top surface. The differences observed in the streamlines show how the pin features affect the material movement. As expected, the threaded pin increases the vertical movement. It is known that one of the threads effect on the FSW process is the increase in the vertical movement of the material around the pin [23]. Even without the threading, some amount of vertical material movement takes place. This was reported in [24] for a cylindrical unthreaded pin. The path of the two points which are not affected by the threaded pin movement passes around the featureless pin. Hence, separation of the streamlines on the advancing side around the featureless pin is observed.
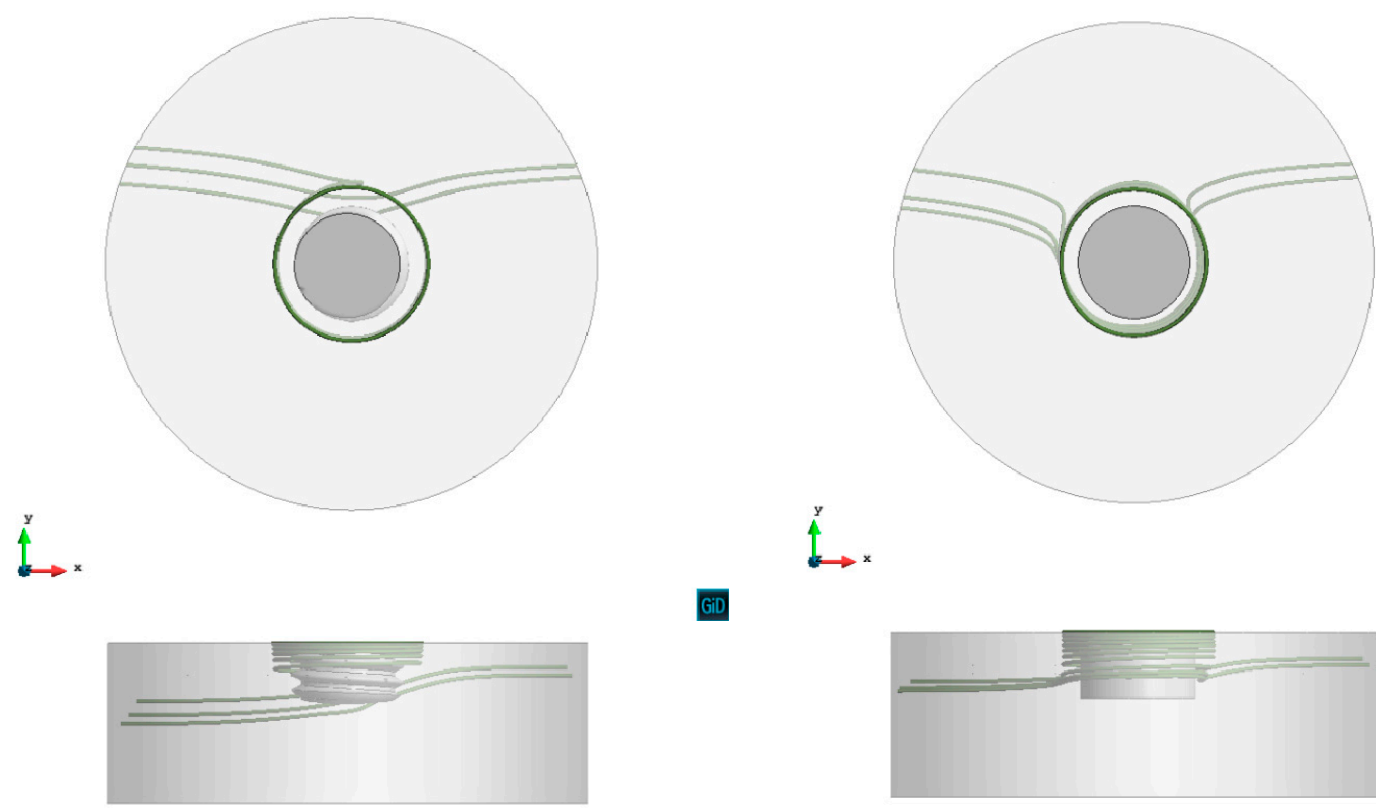

Gii

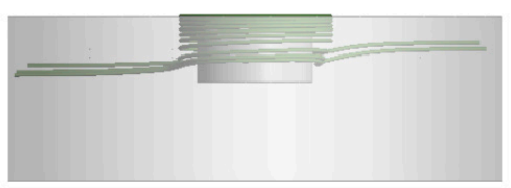

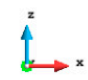

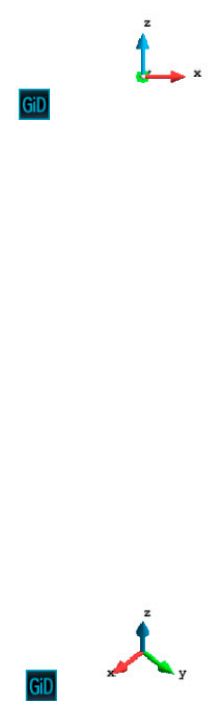

(a)

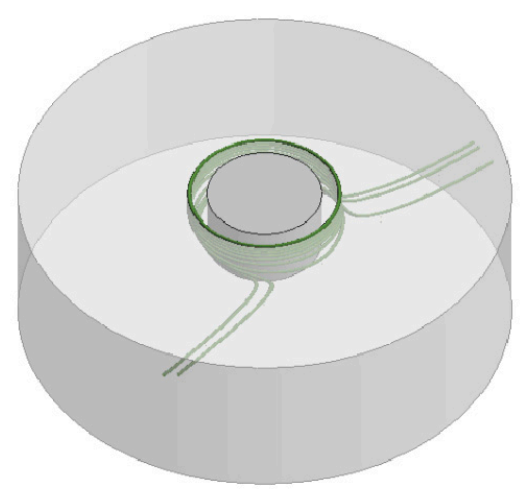

(b)

Figure 13. Velocity streamlines around the tool. (a) Threaded pin; (b) Featureless pin. 


\section{Summary and Conclusions}

In this work, numerical simulations and the experimental calibration of a fast and accurate FEM (Finite Element Analysis) model for FSW analysis of a threaded cylindrical tool pin are presented. The main characteristics of the model are:

- Coupled thermo-mechanical scheme;

- Simulation of arbitrary pin shapes;

- Heat generation due to both friction and plastic dissipation;

- Piecewise linear viscoplastic constitutive model;

- Two-stage strategy for a significantly reduction of computational time;

- Enhanced friction model accounting for the effect of non-uniform pressure distribution.

The results of the FSW simulation using a threaded tool pin are presented in terms of longitudinal, transversal and vertical forces, torque, as well as temperature distribution and compared with the experimental evidence. The agreement between the numerical and experimental results, both in terms of thermal and mechanical behaviours, is remarkable.

A comparison between the thermo-mechanical responses in FSW using threaded and featureless cylindrical pins is also presented. Somewhat lower values of forces and torque are observed in case of threaded pin than featureless one. The non-uniform distribution of heat generation around the tool using the enhanced friction model is more visible in case of using a threaded pin. The threaded tool pin is found to increase the vertical movement of the surrounding material.

It is shown that the proposed numerical model for the simulation of the FSW process is capable of capturing the thermo-mechanical responses with remarkable accuracy for both featureless and threaded pin tools.

Acknowledgments: Financial support from European Council-H2020 MG-2015_SingleStage-A Program under EMUSIC Project-Efficient Manufacturing for Aerospace Components Using Additive Manufacturing, Net Shape HIP and Investment Casting—-is gratefully acknowledged.

Author Contributions: Narges Dialami, Miguel Cervera and Michele Chiumenti developed the numerical model; Antonio Segatori and Wojciech Osikowicz designed and performed the experiments; Narges Dialami analyzed the data.

Conflicts of Interest: The authors declare no conflict of interest.

\section{References}

1. Ilangovan, M.; Rajendra Boopathy, S.; Balasubramanian, V. Effect of tool pin profile on microstructure and tensile properties of friction stir welded dissimilar AA6061-AA5086 aluminium alloy joints. Def. Technol. 2015, 11, 174-184. [CrossRef]

2. Reza-E-Rabby, M.; Reynolds, A.P. Effect of tool pin thread forms on friction stir weldability of different aluminum alloys. Procedia Eng. 2014, 90, 637-642. [CrossRef]

3. Papahn, H.; Bahemmat, P.; Haghpanahi, M.; Pour Aminaie, I. Effect of friction stir welding tool on temperature, applied forces and weld quality. IET Sci. Meas. Technol. 2015, 9, 475-484. [CrossRef]

4. Rezaee Hajideha, M.; Farahani, M.; Davoud Alavi, S.A.; Molla Ramezani, N. Investigation on the effects of tool geometry on the microstructureand the mechanical properties of dissimilar friction stir welded polyethylene and polypropylene sheets. J. Manuf. Process. 2017, 26, 269-279. [CrossRef]

5. Yu, Z.; Zhang, W.; Choo, H.; Feng, Z.L. Transient heat and material flow modeling of friction stir processing of magnesium alloy using threaded tool. Metall. Mater. Trans. A 2012, 43, 724-737. [CrossRef]

6. Colegrove, P.A.; Shercliff, H.R. 3-Dimensional CFD modelling of flow round a threaded friction stir welding tool profile. J. Mater. Process. Technol. 2005, 169, 320-327. [CrossRef]

7. Atharifar, H.; Lin, D.; Kovacevic, R. Numerical and experimental investigations on the loads carried by the tool during friction stir welding. J. Mater. Eng. Perform. 2009, 18, 339-350. [CrossRef]

8. Mishra, R.S.; Ma, Z.Y. Friction Stir Welding and Processing; ASM International: Geauga County, OH, USA, 2007. 
9. Chiumenti, M.; Cervera, M.; Agelet de Saracibar, C.; Dialami, N. Numerical modeling of friction stir welding processes. Comput. Methods Appl. Mech. Eng. 2012, 254, 353-369. [CrossRef]

10. Dialami, N.; Chiumenti, M.; Cervera, M.; Agelet de Saracibar, C. An apropos kinematic framework for the numerical modeling of friction stir welding. Comput. Struct. 2013, 117, 48-57. [CrossRef]

11. Dialami, N.; Chiumenti, M.; Cervera, M.; Agelet de Saracibar, C.; Ponthot, J.-P. Material Flow Visualization in Friction Stir Welding via Particle Tracing. Int. J. Metal Form. 2015, 8, 167-181. [CrossRef]

12. Dialami, N.; Cervera, M.; Chiumenti, M.; Agelet de Saracibar, C. Local-global strategy for the prediction of residual stresses in FSW processes. Int. J. Adv. Manuf. Technol. 2017, 88, 3099-3111. [CrossRef]

13. Dialami, N.; Chiumenti, M.; Cervera, M.; Agelet de Saracibar, C. Challenges in thermo-mechanical analysis of friction stir welding processes. Arch. Comput. Methods Eng. 2017, 24, 189-225. [CrossRef]

14. Dialami, N.; Chiumenti, M.; Cervera, M.; Agelet de Saracibar, C. A fast and accurate two-stage strategy to evaluate the effect of the pin tool profile on metal flow, torque and forces during friction stir welding. Int. J. Mech. Sci. 2017, 122, 215-227. [CrossRef]

15. Dialami, N.; Chiumenti, M.; Cervera, M.; Segatori, A.; Osikowicz, W. Enhanced friction model for friction stir welding (FSW) analysis: Simulation and experimental validation. Int. J. Mech. Sci. 2017, 133, 555-567. [CrossRef]

16. Ryzhakov, P.; Rossi, R.; Oñate, E. An algorithm for the simulation of thermally coupled low speed flow problems. Int. J. Numer. Methods Fluids 2011, 65, 1217-1230. [CrossRef]

17. Ravichandran, G.; Rosakis, A.J.; Hodowany, J.; Rosakis, P. On the conversion of plastic work into heat during high strain rate deformation. AIP Conf. Proc. 2002, 620, 557.

18. Nandan, R.; DebRoy, T.; Bhadeshia, H.K.D.H. Recent advances in friction stir welding-Process, weldment structure and properties. Prog. Mater. Sci. 2008, 53, 980-1023. [CrossRef]

19. Chao, Y.J.; Qi, X.; Tang, W. Heat transfer in friction stir welding-Experimental and numerical studies. J. Manuf. Sci. Eng. 2003, 125, 138-145. [CrossRef]

20. Khandkar, M.Z.H.; Khan, J.A.; Reynolds, A.P.; Sutton, M.A. Predicting residual stresses in friction stir welded metals. J. Mater. Process. Technol. 2006, 174, 195-203. [CrossRef]

21. Serio, L.; Palumbo, D.; Galietti, U.; De Filippis, L.; Ludovico, A. Effect of friction stir process parameters on the mechanical and thermal behavior of 5754-H111 aluminum plates. Materials 2016, 9, 122. [CrossRef] [PubMed]

22. De Filippis, L.; Serio, L.; Palumbo, D.; De Finis, R.; Galietti, U. Optimization and characterization of the friction stir welded sheets of AA5754-H111: Monitoring of the quality of joints with thermographic techniques. Materials 2017, 10, 1165. [CrossRef] [PubMed]

23. Seidel, T.U.; Reynolds, A.P. Visualization of the material flow in AA2195 friction-stir welds using a marker insert technique. Metall. Mater. Trans. A 2001, 32, 2879-2884. [CrossRef]

24. Mishra, R.S.; De, P.S.; Kumar, N. Fundamentals of the friction stir process. In Friction Stir Welding and Processing; Springer: Berlin, Germany, 2014; pp. 13-58.

(C) 2017 by the authors. Licensee MDPI, Basel, Switzerland. This article is an open access article distributed under the terms and conditions of the Creative Commons Attribution (CC BY) license (http://creativecommons.org/licenses/by/4.0/). 